\title{
Letters
}

\section{The Effects of 4-Hydroxybenzoic Acid Identified from Bamboo (Dendrocalamus asper) Shoots on Kv1.4 Channel}

Submitted: 11 Jun 2017

Accepted: 30 Dec 2017

Online: 28 Feb 2018

\author{
Jingli Zhang ${ }^{2}$, Fatin H. MohamaD ${ }^{2}$, Jia Hui Wong ${ }^{2}$, Habsah \\ Mohamad $^{3}$, Abdul Hadi Ismail ${ }^{3}$, Abdul Aziz Mohamed Yusoff ${ }^{1,2}$, \\ Hasnah OsmaN ${ }^{5}$, Kok Tong Wong ${ }^{5}$, Zamzuri IDrIs ${ }^{1,2,4}$, Jafri Malin \\ Abdullah ${ }^{1,2,4}$ \\ 1 Center for Neuroscience Services and Research, Universiti Sains Malaysia, \\ Jalan Hospital Universiti Sains Malaysia, 16150 Kubang Kerian, Kelantan, \\ Malaysia \\ 2 Department of Neurosciences, School of Medical Sciences, Universiti Sains \\ Malaysia, Jalan Hospital Universiti Sains Malaysia, 16150 Kubang Kerian, \\ Kelantan, Malaysia \\ 3 Institute of Marine Biotechnology, Universiti Malaysia Terengganu, \\ 21030 Kuala Terengganu, Terengganu, Malaysia \\ 4 Department of Neurosciences, Hospital Universiti Sains Malaysia, \\ Jalan Hospital Universiti Sains Malaysia, 16150 Kubang Kerian, \\ Kelantan, Malaysia \\ 5 School of Chemical Sciences, Universiti Sains Malaysia, 1180o USM, \\ Pulau Pinang, Malaysia
}

To cite this article: Zhang J, Mohamad FH, Wong JH, Mohamad H, IsmaiL AH, Mohamed Yusoff AA, Osman H, Wong KT, Idris Z, Abdullah JM. The effects of 4-hydroxybenzoic acid identified from bamboo (Dendrocalamus asper) shoots on Kv1.4 channel. Malays J Med Sci. 2018;25(1):101-113. https://doi.org/10.21315/ mjms2018.25.1.12

To link to this article: https://doi.org/10.21315/mjms2018.25.1.12

\section{Abstract}

Background: Bamboo shoot has been used as a treatment for epilepsy in traditional Chinese medicine for generations to treat neuronal disorders such as convulsive, dizziness and headaches. 4-hydroxybenzoic acid (4-hba) is a non-flavonoid phenol found abundantly in Dendrocalamus asper shoots (bamboo), fruits (strawberries and apples) and flowers. Kv1.4 is a rapidly inactivating Shaker-related member of the voltage-gated potassium channels with two inactivation mechanisms; the fast $\mathrm{N}$-type and slow $\mathrm{C}$-type. It plays vital roles in repolarisation, hyperpolarisation and signaling the restoration of resting membrane potential through the regulation of the movement of $\mathrm{K}^{+}$across the cellular membrane.

Methods: Chemical compounds from Dendrocalamus asper bamboo shoots were purified and identified as major palmitic acids mixed with other minor fatty acids, palmitic acid, 4-hydroxybenzaldehyde, lauric acid, 4-hydroxybenzoic acid and cholest-4-ene-3-one. The response of synthetic 4-hydroxybenzoic acid was tested on Kv1.4 potassium channel which was injected into viable oocytes that was extracted from Xenopus laevis. The current were detected by the two-microelectrode voltage clamp, holding potential starting from $-80 \mathrm{mV}$ with $20 \mathrm{mV}$ stepup until $+80 \mathrm{mV}$. Readings of treatments with $0.1 \%$ DMSO, 4-hba concentrations and $\mathrm{K}$ channel blockers were taken at $+60 \mathrm{mV}$. The ratio of tail/peak amplitude is the index of the activity of the Kv1.4 channels with $n \geq 6$ (number of oocytes tested). The decreases of the ratios of five different concentrations (1 $\mu \mathrm{M}, 10 \mu \mathrm{M}, 100 \mu \mathrm{M}, 1 \mathrm{mM}$ and $2.5 \mathrm{mM})$ were compared with $0.1 \%$ DMSO as the control. 
Results: All concentration showed statistically significant results with $P<0.05$ except for $100 \mu \mathrm{M}$. The normalised current of the 4-hba concentrations were compared with potassium channel blockers (TEA and 4-AP) and all groups showed statistically significant results. This study also showed that time taken for each concentration to affect Kv1.4 does not play any significant roles.

Conchusion: 4-hydroxybenzoic acid was found to be able to enhance the inactivation of Kv1.4 by lowering the membrane potential so that the abnormal neuronal firing can be inhibited. With IC50 slightly higher than $10 \mu \mathrm{M}$, increasing concentrations (100 $\mu \mathrm{M}, 1 \mathrm{mM}$ and $2.5 \mathrm{mM}) \mathrm{had}$ shown to exhibit toxicity effects. The best concentration from this study is $10 \mu \mathrm{M}$ with Hill slope of o.1799.

Keywords: Kv1.4 potassium channel, Xenopus oocytes, 4-hydroxybenzoic acid, membrane potential

\section{Background}

About $40 \%$ of epilepsy cases are refractory to currently available conventional antiepileptic drugs. Many Iranian, African, Indian, and Chinese plants have long been used in folk medicine for the treatment of epilepsy $(1-5)$. The antiepileptic constituent may exist in the form of flavonoids (6), saponins (7), and triterpenoids (8). However, only a few studies have been done on the potential of plants found in Malaysia for the treatment of epilepsy: Myristica fragrance (9), Centella asiatica (10, 11), Orthosiphon stamineus (12), Peperomia pellucida (13), and Acorus calamus (14).

Consequently, Chinese traditional medicine (TCM) suggests that bamboo might be used to prevent epilepsy (5). Bamboo is used as a component to reduce the energy of "fire", and is used to treat hypertension, arteriosclerosis, and cardiovascular disease in TCM. Chinese also utilise bamboo as a traditional medicine for the treatment of febrile disorders, exogenous diseases, cooling blood, and for homeostasis regulation (15). The most nutritious part comes from its shoot. Bamboo shoots have also been reported to contain phytosterol, high potassium content which helps in maintaining normal blood pressure, low sugar sugar content, high fiber and anti-carcinogenic activity (16). The consumption and use of bamboo shoots in TCM has long been practiced and recorded in the book 'Compendium of Materia Medica' during the Ming Dynasty (1368-1644) and was considered as a treasured dish in the Tang Dynasty (618907). The Japanese called it as the 'King of Forest Vegetables'. In addition, with more than 1250 species worldwide, bamboo shoots and roots are very popular in Asian cuisines such as India, Indonesia and Malaysia (17).

D. asper was chosen as few studies have reported on its phytochemical constituents and the antiepileptic activity of bamboo from the genera of Dendrocalamus. So far, taxiphyllin, L-asparagine, 4-hydroxybenzaldehyde, and $\beta$-sitosterol are identified as the main extractives of the shoots of D. Giganteus and D. Hamiltonii.

4-hydroxybenzoic acid (4-hba) is a nonflavonoid phenolic compound from benzoic acid derivatives (BADs) along with other biocompounds such as salicylic acid, gallic acid and vanilic acid (18). It constitutes of aromatic benzene ring, hydroxyl substituent and functional derivative that influences the mechanisms, biological activities and properties (19). It is able to pass through blood vessels, blood brain barriers (BBB) and cerebrospinal fluid (CSF) due to its low molecular weight (138.12074 Da) (20). As to date, there are not many toxicity studies of this compound on human however, it has been recorded to be slightly irritating to skin and eyes and the maximum bodily intake is estimated to be 0.067 $\mathrm{mg} / \mathrm{kg}$ /day (for body weight; $70 \mathrm{~kg}$ ) (21). Other than being used in pharmaceuticals and cosmetic products, 4-hba has been reported to have antifungal, antialgal, antimutagenic, antisickling properties, extrogenic activity and used as trapping agent on hydroxyl radical generation using cerebral ischemia and reperfusion (22).

Voltage-gated potassium channels play essential role in restoring the membrane potential and signaling subsequent action potential during neuronal regulation. It is the most abundant and diverse ionic channel identified in the human body with more than 40 types encoded by more than 70 genes and classified into 12 subfamilies (Kv1-Kv12) (23). Kv1 family (Shaker) is mostly distributed around brain, heart, pancreas and kidney. Even though Kv1.2 is more abundantly found, Kv1.4 exhibits more significant roles in repolarisation and hyperpolarisation of neurons (24). It's A-type or fastly-inactivating current is contributed by 
its two inactivation mechanisms; fast $\mathrm{N}$-type and slow C-type $(25,26)$ which helps in many physiological processes including the quantal release of neurotransmitters (27), neuronal excitation, cardiac action potential, muscle contraction, hormonal secretion, transporting electrolytes for epithelial, cell volume and cell proliferation in neuronal and non-neuronal cells (28). Research showed that the contribution of the inactivation components of potassium voltage-gated channel Kv1.4 can inhibit the excitement of action potentials, reducing irregular high frequency depolarisation in neuronal disorders such as epilepsy and fits (29).

The channel consists of 6 transmembrane and one pore which are grouped into voltagesensor domain $\left(\mathrm{S}_{1}-\mathrm{S}_{4}\right)$, a pore domain or selectivity filter ( $\left.\mathrm{S}_{5}-\mathrm{S} 6\right)$ and a re-entrant P-loop region $\left(\mathrm{S}_{4}-\mathrm{S}_{5} \mathrm{loop}\right)(30,31)$. The opening of the pore is regulated by the movement of the voltage sensor domain in monitoring the $\mathrm{K}^{+}$current flow and balance (32). The opening and closing of the selectivity filter is vital in influencing the membrane potential and signaling of inactivation and activation of the channel (28).

In this study, we isolated compounds from D. asper using column chromatography (CC) and thin-layer chromatography (TLC). The compounds identified were then studied to see their effects on Kv1.4 channel separately. This manuscript reports on one of these compounds: 4-hydroxybenzoic acid identified from $D$. asper shoots by in-vitro study using $X$. laevis oocytes.

\section{Materials and Methods}

The flowchart of the experiment methodology is attached as Appendix A.

\section{Purification and Characterisation of Biocompounds from Dendrocalamus asper Shoots}

A total of $44 \mathrm{~kg}$ of bamboo shoots from Dendrocalamus asper were harvested from Post Brooke village in Gua Musang Kelantan at longitude 101.4882616000 and latitude 4.6745201000 on the 14th May 2014. The shoots were identified by Assistant Botanist, Muhammad bin Deraman, from the South Kelantan Development Authority (KESEDAR); the voucher specimen was labeled DAPB52014 and kept at the Department of Neuroscience School of Medical Sciences, Universiti Sains
Malaysia. The outer layers of the bamboo shoots were peeled, and the inner parts were chopped into about $1-2 \mathrm{~cm}^{3}$ pieces and stored in a $-20{ }^{\circ} \mathrm{C}$ chest freezer before further extraction processes. The chopped bamboo shoots were lyophilised and ground to yield $6 \mathrm{~kg}$ dried powder of bamboo shoots. One $\mathrm{kg}$ of dried bamboo shoot powder was extracted three times using dichloromethane. The extracts were dried using a rotary evaporator (Buchi, Essen, Germany) under reduced pressure, below $40{ }^{\circ} \mathrm{C}$ to yield $31.5 \mathrm{~g}$ of dichloromethane extract. Next, $30 \mathrm{~g}$ of dichloromethane extract were subjected to column chromatography $(4 \times 30 \mathrm{~cm}$, dxh) using silica gel (Merck 1.09385.1000) and eluted with chloroform, and then gradiently increased using ethyl acetate and methanol. The fractions were monitored using thin layer chromatography (Merck 1.05735 silica gel 60 F254). The fractions containing the same spot were combined. $2.5 \mathrm{~g}$ of the fractions with the spot on TLC showing $\mathrm{R}_{\mathrm{f}}$ value 0.4 (chloroform/ ethyl acetate, 9:1 v/v) were then subjected to repeated column chromatography $(1 \times 25 \mathrm{~cm}$, dxh) using silica gel (Merck 1.09385.1000) and eluted with hexane/acetone, $7: 3 \mathrm{v} / \mathrm{v}$. Fractions containing the desired spot were recrystallised from hexane/methanol to afford $200 \mathrm{mg}$ of 4-hydroxybenzaldehyde. Purification of fractions containing the spot with $\mathrm{R}_{\mathrm{f}}$ value of 0.7 [hexane: acetone $(2: 8 \mathrm{v} / \mathrm{v})$ ] by repeated column chromatography (CC) on Sephadex LH2O afforded 4-hydroxybenzoic acid. Repeated CC on silica gel of fractions containing the spot with $R_{f}$ value of 0.5 [hexane: ethyl acetate (8:2 $\mathrm{v} / \mathrm{v})$ ] followed by preparative TLC afforded cholest-4-ene-3-one. Lauric acid and palmitic acid were purified from the respective fractions by recrystallisation from hexane/methanol. Biocompounds isolated were identified using co-TLC comparing synthetic compounds and purified biocompounds from the extraction process. Chemical structures of all compounds were elucidated by using spectroscopic data of Electron impact-Mass spectrometry (EIMS) and Nuclear Magnetic Resonance Spectroscopy (NMR). EIMS were recorded by Shimadzu GCMS-QP5050 (Shimadzu, Kyoto, Japan). NMR data were recorded using BrukerAvance40o $\mathrm{MHz}$ (BrukerAvance, Massachusetts, USA). The isolation, purification and identification of the biocompounds were all done in Institute of Marine Biotechnology, Universiti Malaysia Terengganu (UMT), Malaysia. 


\section{Drugs}

4-hydroxybenzoic acid was purchased from Sigma Aldrich (cat. no $=240141-50 \mathrm{~g},>$ 99\% purity; Sigma-Aldrich, St. Louis, Missouri, USA), and dissolved in dimethyl sulfoxide (DMSO) in $1 \mathrm{mM}, 10 \mathrm{mM}, 100 \mathrm{mM}, 1 \mathrm{M}$, and 2.5 M. Tetraethylammonium (TEA) (Sigma Aldrich, USA) and 4-aminopyridine (4-AP) (Sigma Aldrich, USA) were dissolved in DMSO in a concentration of $12.5 \mathrm{M}$ and $5 \mathrm{M}$. For 4-hydroxybenzoic acid, TEA, and 4-AP, dilutions were made just prior to the experiment at a ratio of 1:1000.

\section{cDNA Cloning and in vitro Transcription}

cDNA of Kv1.4 were cloned in pCMV vector in $\mathrm{DH}_{5}$ a competent cells. QIAprep Spin Miniprep Kit (Cat. No. 27104) was used for purification of the plasmid cDNA, followed by determination of cDNA concentration using spectrophotometer NanoDrop 2000 (ThermoScientific ${ }^{\mathrm{TM}}$, Massachusetts, USA). Linearisation of plasmid DNA was performed and in vitro transcription was carried out with T7 Transcription Reaction Kit (RiboMax ${ }^{\mathrm{TM}}$ Large Scale RNA production system), followed by DNase I treatment. The cRNA was isolated and purified with RNeasy Mini Kit (Cat. No. 74104) and the concentration of the cRNA was determined using NanoDrop 200o. The solutions were separated into final $4 \mu \mathrm{L} \mathrm{Kv1.4} \mathrm{aliquot} \mathrm{(the}$ final concentration for Kv1.4 cRNA was $5 \mathrm{ng} / \mu \mathrm{L}$ ), and stored at $-80^{\circ} \mathrm{C}(28,33-34)$.

\section{Surgery and cRNA Expression on Xenopus Oocytes}

A female frog was anaesthetised for approximately $15 \mathrm{~min}$ with $1.25 \mathrm{~g}$ MS-222 in $1 / 5$ of $500 \mathrm{~mL}$ tap water buffered with $1.75 \mathrm{~g}$ sodium bicarbonate. In the lateral paramedian area of the lower abdomen, an $8 \mathrm{~mm}$ incision was cut into the skin. The layer of the muscles was separated in order to enter the abdominal cavity. Approximately 5 lobes of oocytes tissues were extracted and muscle and skin layers were sutured separately. The oocyte lobes were placed into a modified OR-2 solution (in $\mathrm{mM}$ : $82 \mathrm{NaCl}, 5 \mathrm{HEPES}, 1 \mathrm{MgCl}_{2}, 2 \mathrm{KCl}, 1 \mathrm{Na}_{2} \mathrm{HPO}_{4}, 1$ ascorbic acid, $\mathrm{pH}$ 7.5) and cut into small pieces. Small pieces of oocyte tissue were treated with type II collagenase $(1 \mathrm{mg} / \mathrm{mL})$ on a rotator for $60 \mathrm{~min}$ at room temperature $\left(22^{\circ} \mathrm{C}-24^{\circ} \mathrm{C}\right)$. The digested oocytes were washed with up to 2 L modified OR-2 solution. The oocytes were placed in modified ND96 solution (in mM: 96 $\mathrm{NaCl}, 2 \mathrm{KCl}, 1 \mathrm{MgCl}_{2}, 1.8 \mathrm{CaCl}_{2}, 5$ HEPES, $1 \mathrm{Na}-$ Pyruvate, $0.01 \mathrm{mg} / \mathrm{mL}$ Gentamycin, $\mathrm{pH} 7.5$ ) in an incubator at $18{ }^{\circ} \mathrm{C}$ overnight (35-38). Only stage $5^{-6}$ developed oocytes were selected under the anatomy microscope Nikon SMZ10oo (Nikon, Tokyo, Japan). About $5 \mathrm{ng} / \mu \mathrm{L}$ of Kv1.4 potassium channels was injected into each oocyte $(33,38)$. The injected oocytes were stored in the modified ND96 solution in an incubator at $18{ }^{\circ} \mathrm{C}$ for at least $48 \mathrm{~h}(37,39)$.

\section{TEVC Test}

TURBO TEC-O3X amplifier (NPI Electronic GmbH, Tamm, Germany), Digidata 1440A (Molecular Devices, LLC, Sunnyvale, California, USA), and pCLAMP 10.3 software (Molecular Devices, LLC, Sunnyvale, CA, USA) were used for data recording. The data were filtered at $100 \mathrm{~Hz}$ and sampled at $500 \mathrm{~Hz}$. Glass pipettes were pulled with vertical puller Narishige PC-10 (Japan) and filled with $3 \mathrm{M} \mathrm{KCl}$, with a resistance of $0.6-1.5 \mathrm{M} \Omega$ (40, 41). Perfusing solution was gravity-driven (ALA-VM4) across the bath chamber (ALA Scientific Instruments, Westbury, NY, USA). ND96 was used as the working physiological solution (in mM: $96 \mathrm{NaCl}$, $2 \mathrm{KCl}, 1 \mathrm{MgCl}_{2}, 1.8 \mathrm{CaCl}_{2}, 5$ HEPES, pH 7.5). For Kv1.4 potassium channel test, the oocytes were voltage clamped at $-80 \mathrm{mV}$. Steps of $+20 \mathrm{mV}$ were added to attain $+80 \mathrm{mV}$. The data clamped at $+60 \mathrm{mV}$ were used for the calculation of Kv1.4 responses. The current traces obtained during each perfusion were recorded. There were 3 different solutions used to bathe/ perfused the impaled oocytes 1) $0.1 \%$ DMSO 2) 4-hydroxybenzoic acid $1 \mu \mathrm{M} / 10 \mu \mathrm{M} / 100 \mu \mathrm{M} / 1$ $\mathrm{mM}$ or $2.5 \mathrm{mM}$ in ND96 3) 4-hydroxybenzoic acid $1 \mu \mathrm{M} / 10 \mu \mathrm{M} / 100 \mu \mathrm{M} / 1 \mathrm{mM}$ or $2.5 \mathrm{mM}$ $+12.5 \mathrm{mM}$ TEA + $5 \mathrm{mM}$ 4-AP in ND96. The peak amplitude of the potassium current at the beginning and the final amplitude at the terminal of Kv1.4 response was calculated offline using pCLAMP software, and the ratio of the final/peak amplitude was determined as an index of the Kv1.4 current.

\section{Data Analysis}

The experiment was arranged into control group (0.1\% DMSO vehicle), positive drug group (ND96 + 4-hydroxybenzoic acid), and the blockers $(12.5 \mathrm{mM}$ TEA and $5 \mathrm{mM} 4$-AP + 4-hydroxybenzoic acid). Therefore, each oocyte will be perfused with 3 different solutions 
containing the same concentration of 4-hba, and each concentration will be repeated $\geq 6$. Each solution was applied for an equilibration period of several seconds before recording was initiated. Dose-response curves were generated and the data fitted by non-linear regression analysis using SigmaPlot software (SPSS, Inc., Chicago, USA). As fast inactivation is a characteristic of Kv1.4 response, a decrease of the ratio means an increase of the Kv1.4 current, while an increase of the ratio means a decrease of the current. Statistical significance was calculated using the unpaired student $t$-test with $P<0.05$; the data were given as mean \pm SE from at least 6 oocytes and $\geq 2$ oocytes batches. Dose-response curves were generated and the data fitted by non-linear regression analysis using SigmaPlot12 software (SPSS, Inc., Chicago, IL, USA).

\section{Results}

\section{Purification of the Biocompounds}

Two phenolic compounds, 4-hydroxybenzoic acid and p-hydroxybenzaldehyde, a ketosteroid, cholest4-en-3-one and common fatty acids; lauric acid and palmitic acid were isolated from the dichloromethane extract of Dendrocalamus asper bamboo shoots. The NMR data of 4-hydroxybenzoic acid were: ${ }^{1} \mathrm{H}$ NMR (MeOD, $400 \mathrm{MHz}$ ): $\delta 7.88$ ( $2 \mathrm{H}$, dd, $\mathrm{J}=8,2 \mathrm{~Hz}$ ), 6.81 (2H, dd, $\mathrm{J}=8,2 \mathrm{~Hz}$ ); and ${ }^{13} \mathrm{C}$ NMR (MeOD, 125 MHz): $\delta$ 170.1, 122.7, 133, 116.1, 163.4. The EIMS data showed the fragmented ion at $\mathrm{m} / \mathrm{z} 138$ $[\mathrm{M}+], 137\left[\mathrm{M}-\mathrm{H}^{+}\right], 121,93,63$. Both the NMR and EIMS spectroscopic data supported the structure of 4-hydroxybenzoic acid. The co-TLC of a standard 4-hydoxybenzoic acid (4-hba) with the purified 4-hydroxybenzoic acid also further supported its identification, and it is present as one of the major compounds in chloroform extract of D. asper (Figure 1).

\section{The Enhancement Effect of 4-hydroxybenzoic Acid on Kv1.4}

Synthetic 4-hydroxybenzoic acid was purchased from Sigma-Aldrich (St. Louis, MO, USA) and dissolved in DMSO. The experiment doses of 4-hydroxybenzoic acid were $1 \mu \mathrm{M}, 10$ $\mu \mathrm{M}, 100 \mu \mathrm{M}, 1 \mathrm{mM}$, and $2.5 \mathrm{mM}$ in ND96. The stock solutions were prepared in DMSO at 1000 times the targeted concentrations. It gives a final $0.1 \%$ DMSO concentration upon dilution of $2 \mu \mathrm{M}$ stock solution with $20 \mathrm{~mL}$ ND96 for each 4-hba

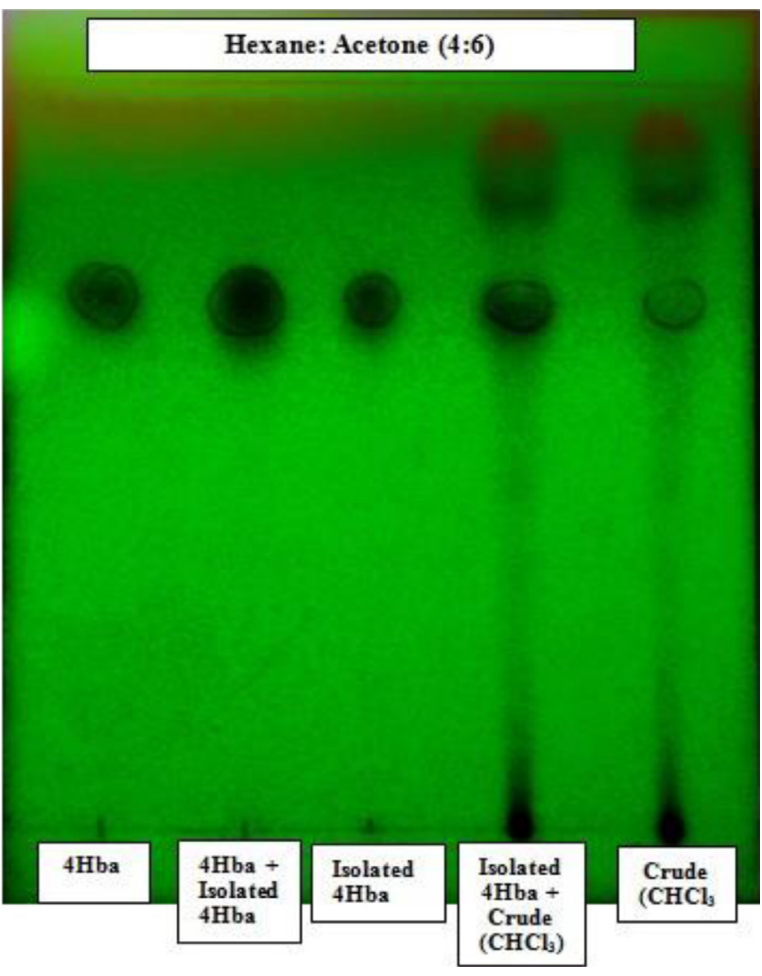

Figure 1. Co-Thin Layer Chromatography (TLC) analysis of crude chloroform extract of Dendrocalamus asper bamboo shoots comparing synthetic 4-hydroxybenzoic acid (4-hba) with its isolated biocompound. Single overlapped spot seen on the same $R_{f}$ value proved that the biocompound is 4 -hba

Note: TLC were done on TLC sheets Merck 1.05735 silica gel $60 \mathrm{~F}_{254}$, solvent system Hexane: Acetone $(4: 6 \mathrm{v} / \mathrm{v})$, observed under $\mathrm{UV}_{254}$

concentrations. Therefore, perfusion with $0.1 \%$ DMSO solution was also carried out as control for the experiment. The ratio of final/peak of the recorded Kv1.4 current response was similar to those of Imbrici et al.'s paper (37). The final and peak ratio values were calculated with pCLAMP software. Enhancement of the Kv1.4 potassium channel is indicated by a decrease of the ratio values while an increase of ratio indicates blockage of the channel. For $1 \mu \mathrm{M}, 10 \mu \mathrm{M}, 1 \mathrm{mM}$, and $2.5 \mathrm{mM}$ 4-hydroxybenzoic acid, there was a significantly more opened Kv1.4 channel. Figure 2 shows an example of current traces obtained during perfusion of each 3 solutions on $10 \mu \mathrm{M}$ 4-hba (all current traces recorded on other concentrations are similar). 

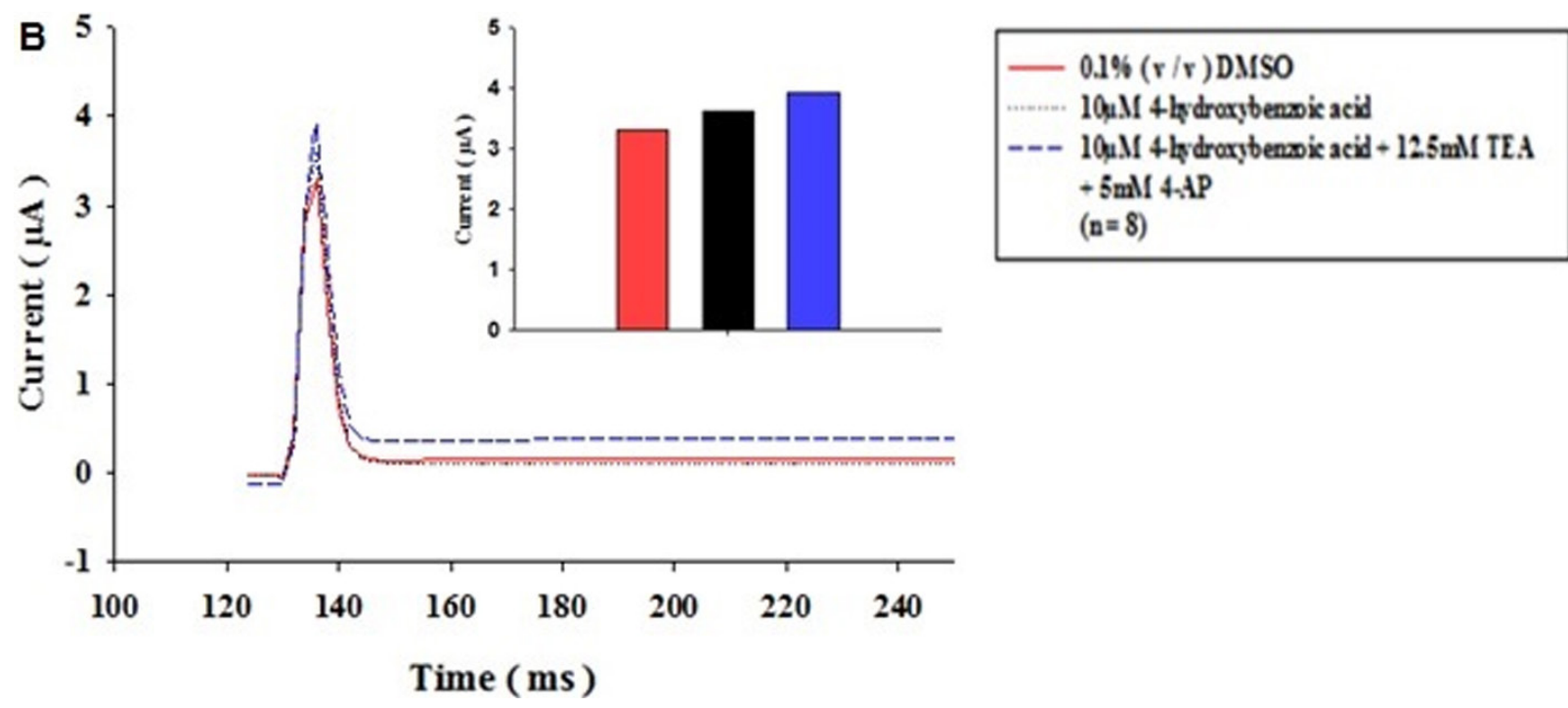

Figure 2. The figure shows an example of current traces of the oocyte when perfused with $0.1 \%$ DMSO (red), $10 \mu \mathrm{M}$ 4-hba (black) and $10 \mu \mathrm{M}$ 4-hba + blockers (blue). Inset plotted graphs represent the highest current value in bar graph. The oocytes were voltage clamped at -80 $\mathrm{mV}$. Step command was added up by $20 \mathrm{mV}$ to $+60 \mathrm{mV}$ for the recording of Kv1.4 channel

The mean of the normalised decrease of the ratio of final/peak of Kv1.4 \pm SE were: 0.4762 $\pm 0.1376,0.3632 \pm 0.1030,0.2933 \pm 0.0844$, and $0.2065 \pm 0.0714$; while $P=0.026(n=7)$, $0.010(n=8), 0.002(n=7)$, and $0.002(n=6)$, compared with each DMSO control, respectively. For $100 \mu \mathrm{M}$ 4-hydroxybenzoic acid, the enhancement effect on Kv1.4 was not significant; the normalised decrease of the ratio was 0.2367 $\pm 0.1531, P=0.383(n=7)$ (Figure 3A).

The perfused solution was turned off once the current trace returned to the equilibrated level (resting potential), which usually takes about 3 min. ND96 was continued to perfuse the system and bath the oocytes for another several minutes to ensure that 4-hba has been completely washed out before the addition of blockers. Two blockers of potassium channel, 12.5 mM TEA + $5 \mathrm{mM}$ 4-AP were added in different doses of 4-hydroxybenzoic acid. In all groups, the addition of $12.5 \mathrm{mM}$ TEA + $5 \mathrm{mM}$ 4-AP significantly blocked the effect of 4-hydroxybenzoic acid on Kv1.4. The ratios of the final/peak of the Kv1.4 response for all doses of 4-hydroxybenzoic acid increased. The largest values of the ratio were selected from 1-5 min after the application of the two blockers, and the highest response mostly came from the 5 th min of blockers application. These responses obtained at the 5 th min of blockers application were compared with the responses from the $5^{\text {th }}$ min of 4-hydroxybenzoic acid groups. For $1 \mu \mathrm{M}, 10 \mu \mathrm{M}, 100 \mu \mathrm{M}, 1 \mathrm{mM}$, and $2.5 \mathrm{mM}$ 4-hydroxybenzoic acid added with 12.5 $\mathrm{mM}$ TEA $+5 \mathrm{mM} 4$-AP, the mean $\pm \mathrm{SE}$ of the normalised increase of the ratio of final/peak of Kv1.4 were: $3.8849 \pm 1.4672(n=7), 1.9510$ $\pm 0.9592(n=8), 1.5071 \pm 0.9338(n=7), 0.4866$ $\pm 0.1468(n=7)$, and $0.0805 \pm 0.0203(n=7)$, respectively $(P<0.001)$ (Figure $3 \mathrm{~B})$.

For $1 \mu \mathrm{M}, 10 \mu \mathrm{M}, 100 \mu \mathrm{M}, 1 \mathrm{mM}$, and 2.5 mM 4-hydroxybenzoic acid groups, the differences of the time of the starting for the enhancement effect of 4-hydroxybenzoic acid on Kv1.4 were $1.5000 \pm 0.3416(n=6), 1.0000$ $\pm 0.0000(n=7), 1.4000 \pm 0.2449(n=5)$, $1.0000 \pm 0.0000(n=10)$, and $1.3333 \pm 0.2108$ ( $n=6) ; P$-values were all $>0.05$. But the $P$-value between the $1 \mu \mathrm{M}$ and $1 \mathrm{mM}$ groups was 0.073, the value nearest to 0.05 (Figure $3 \mathrm{C}$ ). It showed a tendency of the faster effect of 4-hydroxybenzoic acid on the Kv1.4 channel with the increase of the concentration of that chemical.

The enhancement effect disappeared after several minutes. This could be observed from Figure 3D of the time of the maximum effects of the 4-hydroxybenzoic acid on Kv1.4. In $1 \mu \mathrm{M}, 10 \mu \mathrm{M}, 100 \mu \mathrm{M}, 1 \mathrm{mM}$, and $2.5 \mathrm{mM}$ 4-hydroxybenzoic acid groups, the times of the maximum effect of 4-hydroxybenzoic acid on Kv1.4 were $4.1667 \pm 0.4773(n=6), 4.5714$ $\pm 0.2974(n=7), 4.0000 \pm 0.4472(n=5)$, $3.7000 \pm 0.3958(n=10)$, and $4.5000 \pm 0.3416$ $(n=6)$. The $P$-values were all $>0.05$. 
A

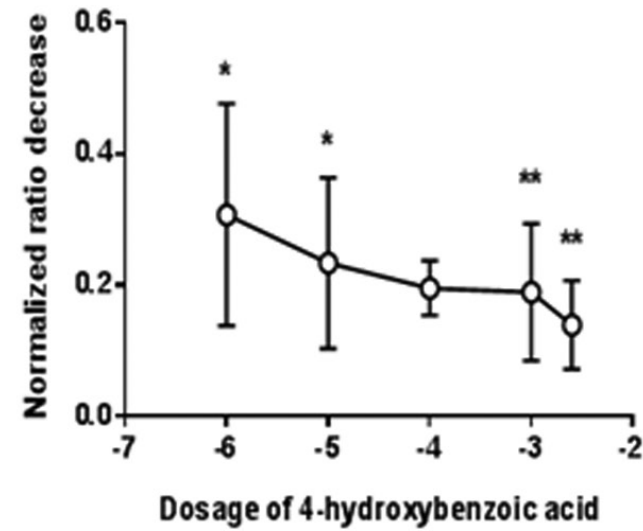

The Effect Time of Earliest Minute by 4-Hydroxybenzoic acid on Kv1.4

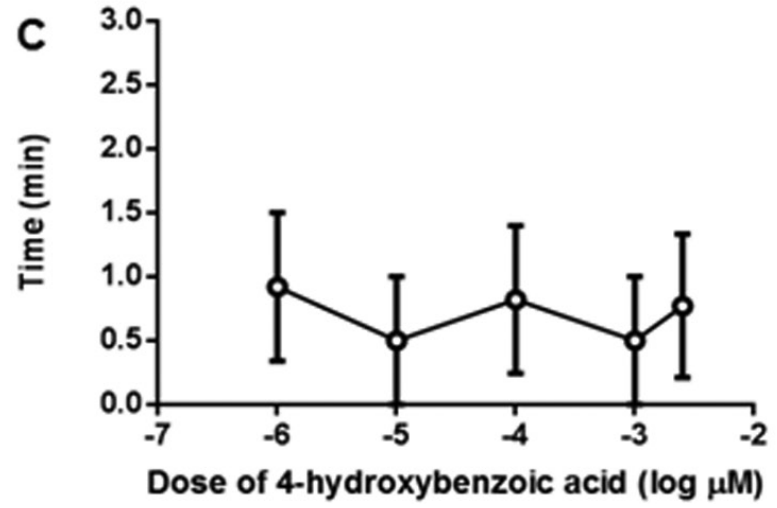

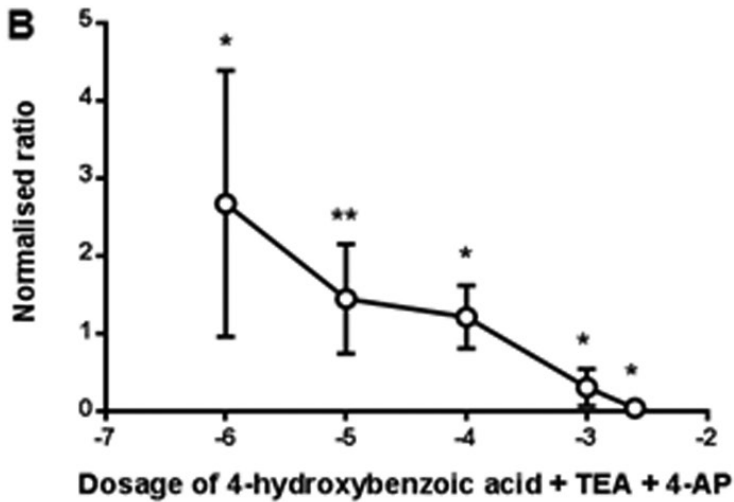

Time of Maximum Effective Minute by 4-Hydoxybenzoic acid on Kv1.4

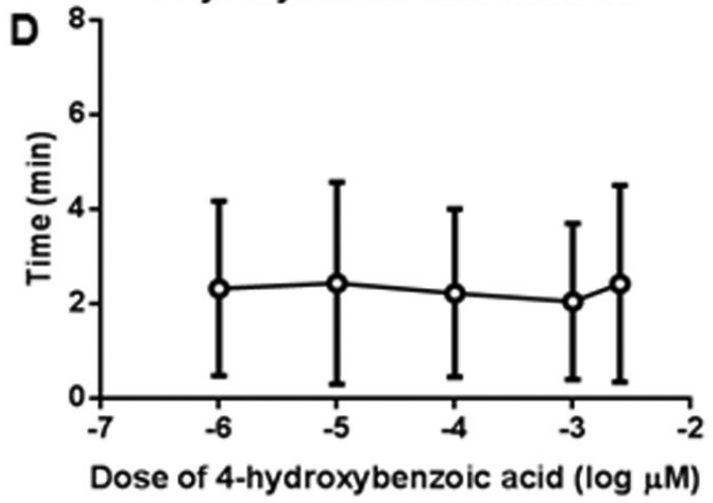

Figure 3. The effects of five different doses of 4-hydroxybenzoic acid on Kv1.4 potassium channels. A: the decrease of the ratio of final/peak of Kv1.4 potassium channel by 5 doses of 4-hydroxybenzoic acid compared with their vehicle (o.1\% DMSO), Hill slope of 0.1799 and $\mathrm{IC}_{50}$ around $10 \mu \mathrm{M} ; \mathbf{B}$ : the increase of the ratio of the different doses under $12.5 \mathrm{mM}$ TEA $+5 \mathrm{mM}$ 4-AP, compared with their ratio at 5 th min of 4-hba; $\mathbf{C}$ : the earliest times under different doses of 4-hydroxybenzoic acid of which ratios showed a decreasing tendency (at $10 \mu \mathrm{M}$ and $1 \mathrm{mM} 4$-hydroxybenzoic acid) compared with their vehicles; D: the times under 5 doses of 4 -hydroxybenzoic acid which ratios were the biggest. ${ }^{*} P<0.05,{ }^{* *} P<0.01$

\section{Discussion}

\section{Kv1.4 Potassium Channel and Its Inactivation}

Kv1.4 channel current recording is characterised by peak that is always upright, going from $-80 \mathrm{mV}$ to $+80 \mathrm{mV}$. The classic Kv1.4 channel is recorded at $+60 \mathrm{mV}$. The Kv1.4 current has a fast N-type inactivation, and a slow constant C-type inactivation when compared with Kv1.1 potassium channel (42). Therefore, the component of Kv1.4 is considered a contribution to inhibit the neuron excitement (43). The parameters of our Kv1.4 channel recording were similar to that cited in the literature (37). The index of the opening of Kv1.4 channel is the decrease in the ratio of the final/ peak, which indicates more inactivation, while the increase in the ratio showed the block of the Kv1.4 channel showing less inactivation. We hypothesise that the enhancement of the Kv1.4 channel expressed in oocytes is a model to treat epilepsy; its main blocker, 4-AP, is a drug to induce epilepsy (44). 


\section{4-hydroxybenzoic Acid on Kv1.4 Potassium Channel}

The effects of $1 \mu \mathrm{M}, 10 \mu \mathrm{M}, 100 \mu \mathrm{M}, 1 \mathrm{mM}$, and $2.5 \mathrm{mM}$ 4-hydroxybenzoic acid on Kv1.4 could all be significantly blocked by $12.5 \mathrm{mM}$ TEA + $5 \mathrm{mM}$ 4-AP. According to references, the contribution of the block effect of TEA is much less than that of 4 -AP $(37,45)$. The time of the effect of $1 \mathrm{mM}$ 4-hydroxybenzoic acid is significantly faster than the $1 \mu \mathrm{M}$ 4-hydroxybenzoic acid. It showed a dose response of the enhancement effect of Kv1.4 by 4-hydroxybenzoic acid. In addition, the time of maximum effect of 4-hydroxybenzoic acid has a tendency to be faster in higher dosages (except for the effect of $2.5 \mathrm{mM}$ 4-hydroxybenzoic acid with $P>0.05$ ).

The inactivation of Kv1.4 is controlled by $\mathrm{N}$ and C-types which results in the nonconducting phase of $\mathrm{K}^{+}$movements across the cellular membrane and repolarisation of the membrane potential. However, these inactivation mechanisms have been shown to be affected by many factors such as $\mathrm{pH}$, extracellular $\mathrm{K}$ ion concentrations and oxidation. The "ball and chain" permeation mechanism of N-type inactivation occurs by blocking the pore by the "ball" preventing the movement of $\mathrm{K}^{+}(46)$. Rapid $\mathrm{N}$-type inactivation is important in developing the C-type, which is hypothesised to involve the selectivity filter, conformational changes, mutations of the pore, quinidine binding (39), intracellular pore closure (47), and osmotic pressure (48). An increase in extracellular $\mathrm{K}^{+}$ concentration enhances the activation of the Kv1.4 channel by binding to the selectivity filter. When the "ball" blocked the pore, the efflux of $\mathrm{K}^{+}$is prevented, reducing the extracellular $\mathrm{K}^{+}$concentration. Thus, the selectivity filter is emptied from $\mathrm{K}^{+}$binding and collapsed $(49,50)$, initiating inactivation. According to Claydon et al. (51) and $\mathrm{Li}$ et al. (52), the selectivity filter is also affected by acidic solution (low pH). As the released of $\mathrm{H}^{+}$competed against the binding to the selectivity filter, it signaled lower $\mathrm{K}^{+}$ concentration within the selectivity filter causing the filter to collapse and hence enhancing the inactivation mechanism. In addition, the inactivation mechanisms of Kv1.4 channels can also be affected by oxidation. The existence of cysteine $(53)$ and methionine $(54,55)$ near the terminals could disrupt the inactivation signaling at the pore, thus enhancing the activation of the channel and causing prolonged depolarisation. This effect can be reversed with anti-oxidation.
As 4-hba is a low acid phenol with a $\mathrm{pk}_{\mathrm{a}}$ of 4.58 , perfusion of the compound on Kv1.4 channel produces a slightly acidic environment which can enhance the inactivation, and helps to lower the membrane potential as targeted. All phenols are classified as anti-oxidant at varying degrees depending on their chemical structure and functional group. Though not as strong as salicylic acid, 4-hba exhibits a stronger anti-oxidation property compared to its other functional group $(56,57)$. Therefore, due to its anti-oxidative property, 4-hba can interfere with the oxidation of the cysteine and methionine residues at the channel pore and influence the development of $\mathrm{N}$ and C-type inactivations.

Figure $3 \mathrm{~A}$ shows that the dose response curve has a Hill slope of 0.1799 , and an $\mathrm{IC}_{50}$ around $10 \mu \mathrm{M}$, which explains the insignificant value obtained at $100 \mu \mathrm{M}$, as its higher concentration is toxic and fails to elicit any further reaction on the Kv1.4 channel. However, the values become significant again at $1.0 \mathrm{mM}$ and $2.5 \mathrm{mM}$. The passive and dormant endogenous ion channels present $\left(\mathrm{Na}^{+}, \mathrm{K}^{+}, \mathrm{Cl}^{-}, \mathrm{Ca}^{2+}\right)$ within the oocytes could have been unintentionally activated by factors such as enhanced hyperpolarisation, higher depolarisation current, acidic extracellular $\mathrm{pH}$, and higher ionic concentrations (58). As the endogenous $\mathrm{Cl}^{-}$channel is the most abundant $(59,60)$ and is important for repolarisation, the activation of the channel will help to lower the membrane potential. Hence, it is able to produce significant values even at concentrations exceeding the $\mathrm{IC}_{50}$ value. Although the effective window of 4-hydroxybenzoic acid on Kv1.4 is very wide, the effective dose of 4-hydroxybenzoic acid should not be so high in vivo during treatment.

\section{Conclusion}

This study demonstrated that
4-hydroxybenzoic acid identified in
Dendrocalamus asper bamboo shoots could
enhance the activities of Kv1.4 potassium
channels, contributing to the reduction of
membrane excitation. These findings provided
us new leads to further identify and examine
other compounds found in D. asper bamboo
shoots with potential antiepileptic properties as
bamboo is one of the important medicinal plants
in traditional Chinese medicine. This is the first
report on 4-hba identified through the extraction
of $D$. asper on Kv1.4 channel expressed in


Letters | Effect of 4-hydroxybenzoic acid on Kv1.4 channel

$X$. laevis oocytes. We await the results of effects of other biocompounds from $D$. asper on Kv1.4 channel and GABA (A) receptor.

\section{Declarations}

\section{Ethics Approval and Consent to Participate}

This study was approved by The Animal Ethics Committee Universiti Sains Malaysia on the research project titled 'The Anti-Epilepsy Effects of DA1, DA2 and Fraction 57 et al. from Petung Bamboo (Dendrocalamus asper) Shoots on GABA (A) Receptor, GluA1 Receptor and Kv1.4 Channel' for 40 female Xenopus laevis (No. of animal ethics approval: USM/Animal Ethics Approval/2014/ (90) (578)).

\section{Conflict of Interest}

There were no conflicts of interest stated by the authors.

\section{Funds}

The work was funded by the short term grant (304/PPSP/61312047, from Universiti Sains Malaysia), FRGS grant (203/ PPSP/6171155, from Ministry of Higher Education, Malaysia) and the RUI from USM university grant (1001/PPSP/812186) to $\mathrm{Dr}$ Jingli Zhang, Prof Dato Dr Jafri Malin Abdullah, et al.

\section{Acknowledgements}

Wan Burhanuddin bin Wan Abidin Dip Arch (ITM '75), BFA, B.Arch (RISD '79), S. M. Arch. S (MIT '81) (deceased) from the School Of Housing, Building and Planning, Universiti Sains Malaysia initiated the Bamboo Research Cluster, Universiti Sains Malaysia in 2009 and the research into its biocompounds and its effects in epilepsy and other neurological diseases. Professor Dr Shaharum Shamsuddin and his lab in School of Health Sciences, Universiti Sains Malaysia.

\section{Authors' Contributions}

Conception and design: JZ, HM, AAMY, HO, JMA Analysis and interpretation of data: JZ, FHM, JHW, HM, KTW

Drafting of the article: FHM, JHW

Critical revision of the article for important intellectual content: RH, RI Final approval of the article: JZ, HM, AAMY, HO, JMA

Final approval of the article: HM, JMA

Provision of study materials or patients: JZ

Statistical expertise: JZ

Obtaining of funding: JZ, ZI

Administrative, technical, or logistic support: JZ,

AAMY, ZI, JMA

Collection and assembly data: FHM, JHW, AHI

\section{Correspondence}

Dr Jingli Zhang MD, PhD (Military Postgraduate Medical School, Beijing, PR China)

Department of Neurosciences,

School of Medical Sciences, Universiti Sains Malaysia, 16150 Kubang Kerian,

Kelantan, Malaysia.

Tel: +6-097676300

Fax: +6-097673833

E-mail: drjlzhang@gmail.com

\section{References}

1. Nsour WM, CB Lau, Wong IC. Review on phytotherapy in epilepsy. Seizure. 2000;9(2):96107. https://doi.org/10.1053/seiz.1999.0378

2. Muazu J, Kaita AH. A review of traditional plants used in the treatment of epilepsy amongst the Hausa/Fulani tribes of northern Nigeria. Afr. J. Traditional. 2008;5(4):387-390. https://doi. org/10.4314/ajtcam.v5i4.31294

3. Reetesh M, Papiya B, Sunny S, Sonam J. Medicinal plants used in the treatment of epilepsy. Inter Res J Pharmacy. 2011;2(2):3239. https://doi.org/10.1016/j.seizure.2014.01.013

4. Sahranavard S, Ghafari S, Mosaddegh M. Medicinal plants used in Iranian traditional medicine to treat epilepsy. Seizure. 2014;23(5):328-332. https://doi.org/10.1016/j. seizure.2014.01.013

5. Zhu HL, Wan JB, Wang YT, Li BC, Xiang C, He J, et al. Medicinal compounds with antiepileptic/anticonvulsant activities. Epilepsia. 2014;55(1):3-16. https://doi.org/10.1111/epi.12463 
6. Nassiri-Asl M, Shariati-Rad S, Zamansoltani F. Anticonvulsive effects of intracerebroventricular administration of rutin in rats. Prog Neuropsychopharmacol Biol Psychiatry. 2008;32(4):989-993. https://doi.org/10.1016/j. pnpbp.2008.01.011

7. Chindo BA, Anuka JA, McNeil L, Yaro AH, Adamu SS, Amos S, et al. Anticonvulsant properties of saponins from Ficus platyphylla stem bark. Brain Res Bull. 2009;78(6):276-282. https://doi. org/10.1016/j.brainresbull.2008.12.005

8. Muceniece R, Saleniece K, Rumaks J, Krigere L, Dzirkale Z, Mezhapuke R, et al. Betulin binds to $\gamma$-aminobutyric acid receptors and exerts anticonvulsant action in mice. Pharmacol Biochem Behav. 2008;90(4):712-716. https:// doi.org/10.1016/j.pbb.2008.05.015

9. Has ATC, Islam MR, Baburin I. The inhibitory activity of nutmeg essential oil on GABA (A) $\alpha_{1} \beta_{2 \gamma 2 s}$ receptors. Biomedical Research. 2014;25(4):543-550.

10. Abdullah JM. Interesting Asian plants: their compounds and effects on electrophysiology and behaviour. Malaysian Journal of Medical Sciences. 2011;18(4):1-4.

11. Khatun MA, Harun-Or-Rashid M, Rahmatullah M. Scientific validation of eight medicinal plants used in traditional medicinal systems in Malaysia: a review. American-Eurasian Journal of Sustainable Agriculture. 2011;5(1):67-75.

12. Al-Bayaty FH, Abdulla MA, Hassan IA, Hussein SF. Effects of Malaysian medicinal plants on macrophage functions in vitro study. Journal of Medicinal Plants Research. 2010;4(14):14591463.

13. Khan A, Rahman M, Islam MS. Neuropharmacological effects of Peperomia pellucida leaves in mice. DARU. 2008;16(1):3540.

14. Chandrashekar R, Adake P, Rao SN. Anticonvulsant activity of ethanolic extract of Acorus calamus rhizome in Swiss albino mice. Journal of Scientific and Innovative Research. 2013;2(5):846-851.

15. Sun J, Yue Y-D, Tang F, Guo X-F. Coumarins from the leaves of Bambusa pervariabilis McClure. $J$ Asian Nat Prod Res. 2010;12(3):248-251. https://doi. org/10.1080/10286020903578658
16. Chongtham N, Bisht MS, Haorongbam S. Nutritional properties of bamboo shoots: potential and prospects for utilization as a health food. Comprehensive Reviews in Food Science and Food Safety. 2011;10(3):153-168. https:// doi.org/10.1111/j.1541-4337.2011.00147.x

17. Nongdam $P$, Tikendra L. The nutritional facts of bamboo shoots and their usage as important traditional foods of Northeast India. Int Sch Res Notices. 2014;2014:679073. https://doi. org/10.1155/2014/679073

18. Camusso W, Sacco S, Maffei M, Bertea CM. Effect of benzoic acid hydroxyl- and methoxyring substituents on cucumber (Cucumis sativus L.) root membrane potential. Journal of Plant Interactions. 2007;2(3):185-193. https://doi. org/10.1080/17429140701596349

19. Oksana S, Marian B, Mahendra R, Bo SH. Plant phenolic compounds for food, pharmaceutical and cosmetics production. Journal of Medicinal Plants Research. 2012;6(13): 2526-2539.

20. Drugbank. p-Hydroxybenzoic acid. 2017 [cited December 29, 2017]. Available from: https:// www.drugbank.ca/drugs/DBo4242.

21. Organization for Economic Cooperation and Development (OECD). SIDS initial assessment report: 4-hydroxybenzoic acid; 1999.

22. Manuja R, Sachdeva S, Jain A, Chaudhary JA comprehensive review on biological activities of p-hydroxy benzoic acid and its derivatives. Int. $J$. Pharm. Sci. Rev. Res. 2014;22:109-115.

23. D'Adamo MC, Catacuzzeno L, Di Giovanni G, Franciolini F, Pessia M. K(+) channelepsy: progress in the neurobiology of potassium channels and epilepsy. Front Cell Neurosci. 2013;7:134. https://doi.org/10.3389/fncel.2013. 00134

24. Gutman GA, Chandy KG, Grissmer S, Lazdunski M, Mckinnon D, Pardo LA, et al. International Union of Pharmacology. LIII. Nomenclature and molecular relationships of voltagegated potassium channels. Pharmacol Rev. 2005;57(4):473-508. https://doi.org/10.1124/ pr.57.4.10

25. Oliva C, Gonzalez V, Naranjo D. Slow inactivation in voltage gated potassium channels is insensitive to the binding of pore occluding peptide toxins. Biophys J. 2005;89(2):1009-1019. https://doi. org/10.1529/biophysj.105.060152 
26. Gonzalez-Perez V, Neely A, Tapia C, GonzálezGutiérrez G, Contreras G, Orio P, et al. Slow inactivation in Shaker $\mathrm{K}$ channels is delayed by intracellular tetraethylammonium. $J$ Gen Physiol. 2008;132(6):633-650. https://doi.org/10.1085/ jgp.200810057

27. Trimmer JS, Rhodes KJ. Localization of voltagegated ion channels in mammalian brain. Annu Rev Physiol. 2004;66:477-519. https://doi. org/10.1146/annurev.physiol.66.032102.113328

28. Lee JH, Choi S-H, Lee B-H, Shin T-J, Pyo MK, Hwang S-H, et al. The effects of ginsenoside Rg3 on human Kv1.4 channel currents without the N-terminal rapid inactivation domain. Biol. Pharm. Bull. 2009;33(4):614-618. https://doi. org/10.1248/bpb.32.614

29. Wulff H, Castle NA, Pardo LA. Voltage-gated potassium channels as therapeutic targets. Nat Rev Drug Discov. 2009;8(12):982-1001. https:// doi.org/10.1038/nrd2983

30. Chanda B, Bezanilla F. A common pathway for charge transport through voltage-sensing domains. Neuron. 2008;57(3):345-351. https:// doi.org/10.1016/j.neuron.2008.01.015

31. Barros F, Dominguez P, de la Pena P. Cytoplasmic domains and voltage-dependent potassium channel gating. Front Pharmacol. 2012;3:49. https://doi.org/10.3389/fphar.2012.00049

32. Rodriguez-Menchaca AA, Adney SK, Tang Q-Y, Meng X-Y, Rosenhouse-Dantsker A, Cui M, et al. PIP2 controls voltage-sensor movement and pore opening of $\mathrm{Kv}$ channels through the S4-S5 linker. Proc Natl Acad Sci USA. 2012;109(36):E2399-E2408. https://doi.org/10. 1073/pnas.1207901109

33. Zhang J, Yusoff AAM. A simple protocol of electrophysiological assays of $\alpha_{1} \beta 2 \gamma 2 s$ GABA (A) receptor in Xenopus oocytes. Kuala Lumpur, Malaysia: National Library of Malaysia; 2015.

34. Sambrook J, Russell DW. Molecular cloning, a laboratory manual, Volume 3 (3rd ed.). Cold Spring Harbor, New York, USA: Cold Spring Harbor Laboratory Press; 2001.
35. Dascal N, Doupnik CA, Ivanina T, Bausch S, Wang W, Lin C, et al. Inhibition of function in Xenopus oocytes of the inwardly rectifying G-protein-activated atrial $\mathrm{K}$ channel (GIRK1) by over expression of a membrane-attached form of the C-terminal tail. Proc Natl Acad Sci. 1995;92(15):6758-6762. https://doi.org/ 10.1073/pnas.92.15.6758

36. O'Connell D, Mruk K, Rocheleau JM, Kobertz WR. Xenopus laevis oocytes infected with multidrug-resistant bacteria: implications for electrical recordings. J Gen Physiol. 2011;138(2): 271-277. https://doi.org/10.1085/jgp.201110661

37. Imbrici P, D'Adamo MC, Grottesi A, Biscarini A, Pessia M. Episodic ataxia type 1 mutations affect fast inactivation of $\mathrm{K}+$ channels by a reduction in either subunit surface expression or affinity for inactivation domain. Am $J$ Physiol Cell Physiol. 2011;300(6):C1314-C1322. https://doi. org/10.1152/ajpcell.oo456.2010

38. Kobayashi T, Ikeda K, Kumanishi T. Episodic ataxia type 1 mutations affect fast inactivation of $\mathrm{K}+$ channels by a reduction in either subunit surface expression or affinity for inactivation domain. British Journal of Pharmacology. 2002;135:313-322. https://doi.org/10.1038/ sj.bjp.0704475

39. Wang S, Morales MJ, Qu YJ, Bett GC, Strauss HC, Rasmusson RL. Kv1.4 channel block by quinidine: evidence for a drug-induced allosteric effect. The Journal of Physiology. 2003;546(2):387-401. https://doi.org/10.1113/jphysiol.2002.029512

40. Ponce A, Jimenez-Cardoso E, Eligio-Garcia L. Voltage-dependent potassium currents expressed in Xenopus laevis oocytes after injection of mRNA isolated from trophozoites of Giardia lamblia (strain Portland-1). Physiol Rep. 2013;1(7):eo0186. https://doi.org/10.1002/ phy2.186

41. Bierwirtz A, Schwarz W. Two-Electrode Voltage Clamp (TEVC). Biophysikalisches Praktikum Institut fur Biophysik Johann Wolfgang Goethe: Universitat Frankfurt am Main; 2014.

42. Varshney A, Matthew MK. Localization of voltagegated ion channels in mammalian brain. Annu Rev Physiol. 2004;2005(66):477-519 
43. Xie C, Su H, Guo T, Yan Y, Peng X, Cao R, et al. Synaptotagmin I delays the fast inactivation of Kv1.4 channel through interaction with its N-terminus. Molecular Brain. 2014;7(1):4. https://doi.org/10.1186/1756-66o6-7-4

44. Laura MC, Xóchitl F-P, Anne S, Alberto M-V. Analysis of Connexin expression during seizures induced by 4-aminopyridine in the rat hippocampus. $J$ Biomed Sci. 2015;22(69). https://doi.org/10.1186/s12929-015-0176-5

45. Rasmusson RL, Zhang Y, Campbell DL, Comer $\mathrm{MB}$, Castellino R, Liu S, et al. Bi-stable block by 4-aminopyridine of a transient $\mathrm{K}+$ channel (Kv1.4) cloned from ferret ventricle and expressed in Xenopus oocytes. J Physiol. 1995;485(1):5971. https://doi.org/10.1113/jphysiol.1995.sp020712

46. Armstrong CM, Bezanilla F. Negative conductance caused by entry of sodium and cesium ions into the potassium channels of squid axons. $J$. Gen. Physiol. 1972;60:588-608. https://doi. org/10.1085/jgp.60.5.588

47. Bett GC, Rasmusson RL. Inactivation and recovery in Kv1.4 K+ channels: lipophilic interactions at the intracellular mouth of the pore. $J$ Physiol. 2004;556(Pt 1):109-120. https://doi. org/10.1113/jphysiol.2003.055012

48. Jiang $\mathrm{X}$, Bett GC, Li X, Bondarenko VE, Rasmusson RL. C-type inactivation involves a significant decrease in the intracellular aqueous pore volume of Kv1.4 K+ channels expressed in Xenopus oocytes. $J$ Physiol. 2003;549(3):683-695. https://doi.org/10.1113/ jphysiol.2002.034660

49. Hoshi T, Armstrong CM. C-type inactivation of voltage-gated $\mathrm{K}+$ channels: pore constriction or dilation? J. Gen. Physiol. 2013:141(2):151-160. https://doi.org/10.1085/jgp.201210888

50. McAllister RE, Noble D. The time and voltage dependence of the slow outward current in cardiac purkinje fibres. J Physiol. 1966;186:632662. https://doi.org/10.1113/jphysiol.1966.spoo 8060

51. Claydon T, Makary S, Dibb K, Boyett, M.. $\mathrm{K}+$ activation of Kir3.1/Kir3.4 and Kv1.4 K+ channels is regulated by extracellular charges. Biophys J. 2004;87(4):2407-2418. https://doi. org/10.1529/biophysj.103.039073
52. Li X, Bett GC, Jiang X, Bondarenko VE, Morales MJ, Rasmusson RL. Regulation of N- and C-type inactivation of Kv1.4 by pHo and $\mathrm{K}+$ : evidence for transmembrane communication. Am J Physiol Heart Circ Physiol. 2002;284:H71-H8o. https:// doi.org/10.1152/ajpheart.00392.2002

53. Sahoo N, Hoshi T, Heinemann SH. Oxidative modulation of voltage-gated potassium channels. Antioxidants and Redox Signalling. 2014;21(6):933-952. https://doi.org/10.1089/ ars.2013.5614

54. Chen J, et al. Acceleration of P/C-type inactivation in voltage-gated $\mathrm{K}+$ channels by methionine oxidation. Biophysical Journal. 2000:78:174-187. https://doi.org/10.1016/ Sooo6-3495(oo)76583-0

55. Ciorba MA, et al. Modulation of potassium channel function by methionine oxidation and reduction. Proc Natl Acad Sci. 1997;94:99329937. https://doi.org/10.1073/pnas.94.18.9932

56. Merkl R, HRádkoVá I, FIlIp V, ŠMIdRkal J. Antimicrobial and antioxidant properties of phenolic acids alkyl esters. Czech J. Food Sci. 2010;28(4):275-279.

57. Simic A, Manojlović D, Šegan D, Todorović M. Electrochemical behaviour and antioxidant and prooxidant activity of natural phenolics. Molecules. 2007;12(10):2327-2340. https://doi. org/10.3390/12102327

58. Terhag J, Cavara NA, Hollmann M. Cave canalem: how endogenous ion channels may interfere with heterologous expression in Xenopus oocytes. Methods. 2010;51:66-74. https:/doi. org/10.1016/j.ymeth.2010.01.034

59. Weber W-M. Endogenous ion channels in oocytes of Xenopus laevis: recent developments. J. Membrane Biol. 1999;170:1-12. https://doi. org/10.1007/soo2329900532

6o. Sobczak K, et al. Endogenous transport systems in the Xenopus laevis oocyte plasma membrane. Methods. 2010;51:181-189. https://doi.org/10. 1016/j.ymeth.2009.12.001 


\section{Appendix A}

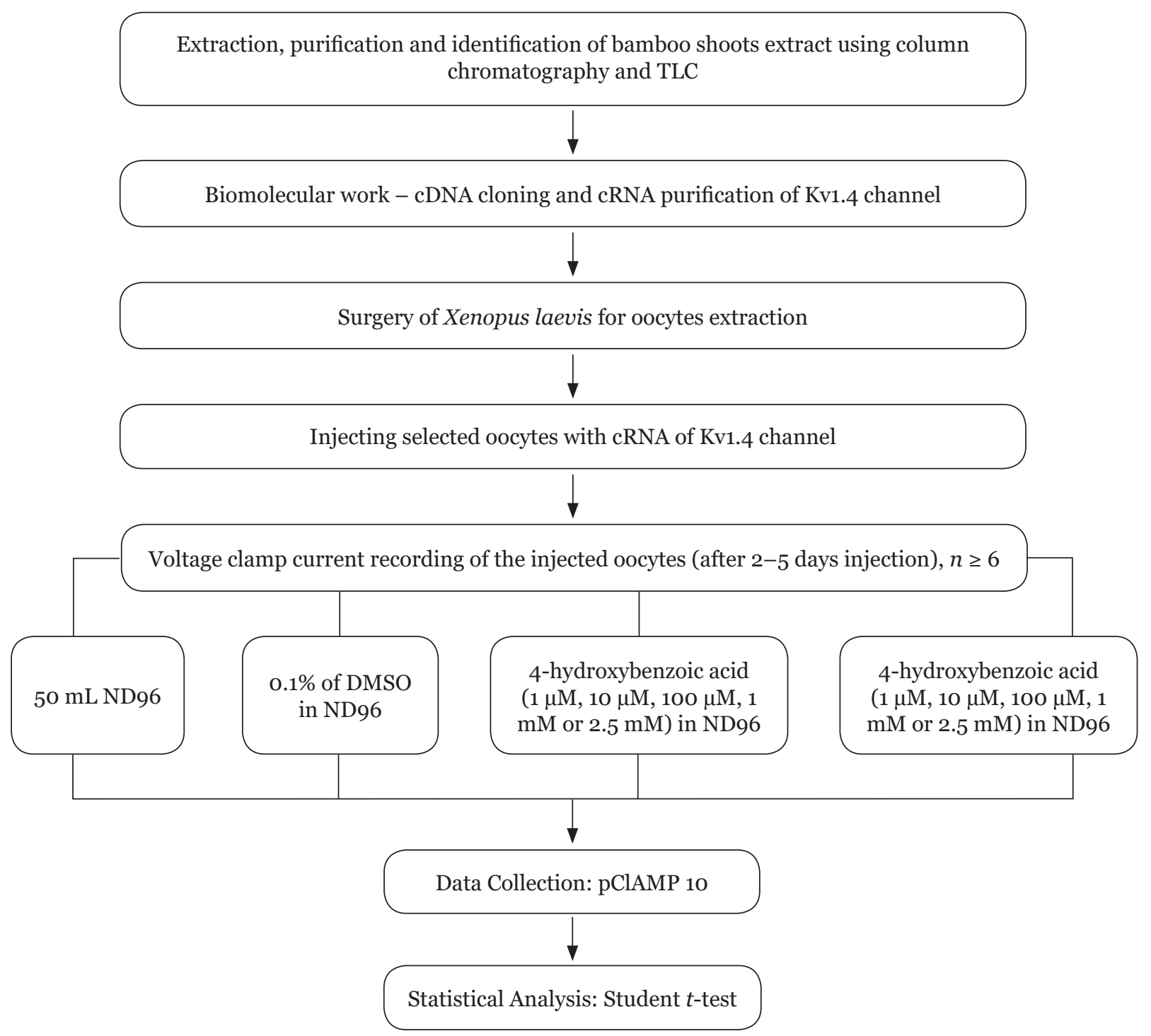

The flowchart of methodology applied in this study 